\title{
Cronología de Germán Colmenares: principales hitos académicos
}

Por: Julián Galindo Zuluaga

1938: nace en la ciudad de Bogotá, el primero de agosto, Germán Pablo Colmenares Colmenares.

1950: ingresa al bachillerato en el Liceo Nacional de Zipaquirá.

1956: termina sus estudios de secundaria en el Liceo Nacional de Zipaquirá. En el mismo año, ingresa a la Facultad de Jurisprudencia, en el Colegio Mayor del Rosario.

1957: ingresa a estudiar — en simultáneo con Derecho - Filosofía y Letras, en la Facultad de Filosofía y Letras de la Universidad Nacional de Colombia, con matrícula de honor.

1960: recibe, el 17 de diciembre, el grado de licenciado en Filosofía y Letras por la Universidad Nacional de Colombia. La ceremonia fue precedida por el decano de la facultad, Dr. Jaime Jaramillo Uribe. Culmina, también, sus estudios en Derecho y es elegido Colegial de Número del Colegio del Rosario.

1961-1962: trabaja como abogado del Ministerio de Hacienda; profesor de tiempo parcial de la Universidad Nacional de Colombia y profesor de cátedra (Historia de la cultura) en la Universidad La Gran Colombia.

1962: recibe, el 31 de agosto, el grado de Doctor en Jurisprudencia, con su tesis titulada Esquema para una historia de las ideas políticas en Colombia durante el siglo $X I X$. El presidente de la tesis, Álvaro Copete Lizarralde; contó con el auspicio intelectual de Antonio Antelo - a quien fue dedicada-.

1963-1964: realiza estudios de posgrado, con especialidad en Historia, en la Universidad de París.

1965-1966: trabaja como profesor de tiempo completo en humanidades, en la Universidad de los Andes.

1967-1968: lleva a cabo estudios de posgrado en la Universidad de Chile, Centro de Investigaciones de Historia Americana. El producto de su tesis, dirigida por Rolando 
Mellafe, se convertiría en el libro Las haciendas de los jesuitas en el Nuevo Reino de Granada.

1969-1970: se vincula como profesor investigador a la Universidad de los Andes.

\section{0:}

- Amplía su trabajo con las investigaciones en el Archivo General de Indias (Sevilla), cobijándose bajo lo que se llamaría escuela sevillana.

- Inicia el doctorado en Historia en la Universidad de París (Nanterre) gracias a una beca de la Fundación Ford. Inscribe sus tesis en el École Pratique des Hautes Études, bajo la tutoría de Fernand Braudel.

- Participa en el Congreso de Americanistas, en Lima.

\section{1:}

- Finaliza, en el corto tiempo de año y medio, el doctorado en la Universidad de París, y recibe una mención Très Bien. Los jurados son Pierre Vilar, Frédéric Mauro y Ruggiero Romano.

- Es profesor invitado en la Universidad de Sevilla.

1972: la Universidad del Valle lo contrata brevemente como decano encargado de la División de Humanidades; posteriormente, como profesor asociado.

1972-1973: con el estímulo de la Corporación para el Fomento de las Investigaciones Económicas, se integra lo que fue su tesis de doctorado bajo el título de Historia social y económica de Colombia 1537-1719.

\section{4:}

- Es elegido representante de los profesores en el Consejo Superior de la Universidad del Valle.

- En junio es designado como profesor titular de la Universidad del Valle.

\section{5:}

- Participa como decano (e) de la División de Humanidades de la Universidad del Valle.

- Realiza una estadía en la Universidad de Berkeley, California, con Woodrow Borah.

- Recibe la beca Guggenheim, concedida por la John Simon Guggenheim Memorial Foundation.

\section{6:}

- Participa en el Congreso de Americanistas, en París. 
- Hace una estadía en el Archivo de Indias.

1977: es profesor visitante ("Tinker Visiting Professor") en la Universidad de Columbia, Nueva York.

\section{2:}

- Participa en el Congreso de Americanistas, en Manchester.

- Es becario por el Woodrow Wilson, Smithsonian Institution (Wilson Center), Washington D. C.

1984: Es profesor invitado en la maestría de Historia Andina, Quito.

\section{5:}

- Participa en el Congreso de Americanistas, en Bogotá.

- Es profesor invitado en la Universidad de Cambridge; Fellow (académico) en el Saint Edmunds House.

1986: Miembro de número de la Academia Colombiana de Ciencias Económicas.

\section{8:}

- Profesor distinguido de la Universidad del Valle.

- Es designado como director de la Maestría en Historia, Universidad del Valle.

1990: fallece en Cali el 27 de marzo, a los 51 años.

\section{Bibliografía}

\section{Fuentes primarias}

“Archivos personales de Germán Colmenares”. Archivo privado de Renán Silva. Bogotá, Colombia.

\section{Fuentes secundarias}

Lozano, Hernán. "Colmenares, un rastro de papel". Historia y espacio [separata] n. ${ }^{\circ}$ 14 (1991): 1-55.

Melo, Jorge Orlando. "Germán Colmenares: una memoria personal”. Boletín Cultural y Bibliográfico 27, ${ }^{\circ}{ }^{\circ} 22$ (1990): 153-155. 